\title{
COMUNICACIÓN JOVEN: A PROPÓSITO DE LA FASCINACIÓN Y LA PRESTACIÓN EDUCATIVA DE LOS NUEVOS MEDIOS
}

Resumen. Este artículo pretende responder a esta pregunta: ¿por qué los lenguajes multimedia gustan tanto a los jóvenes? Después de definir las características de estos lenguajes, se analiza el papel que las nuevas tecnologías juegan en el imaginario de los jóvenes, y se estudian específicamente aquellos factores que podrían contribuir a mejorar su aprendizaje y, en general, su educación. Finalmente, se alude a los procesos cognitivos que subyacen a las actividades que los jóvenes realizan con el ordenador y a las formas de pensamiento y comunicación que promueven estos nuevos medios tecnológicos.

Palabras clave: Comunicación, generación joven, lenguajes multimedia, aprendizaje, multialfabetización, hipertexto

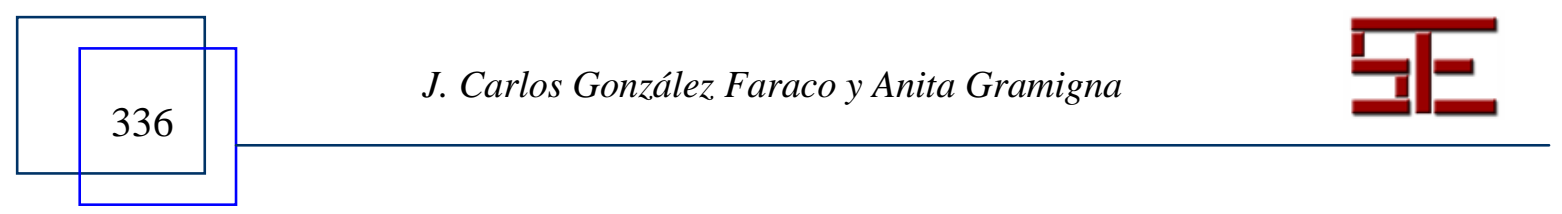




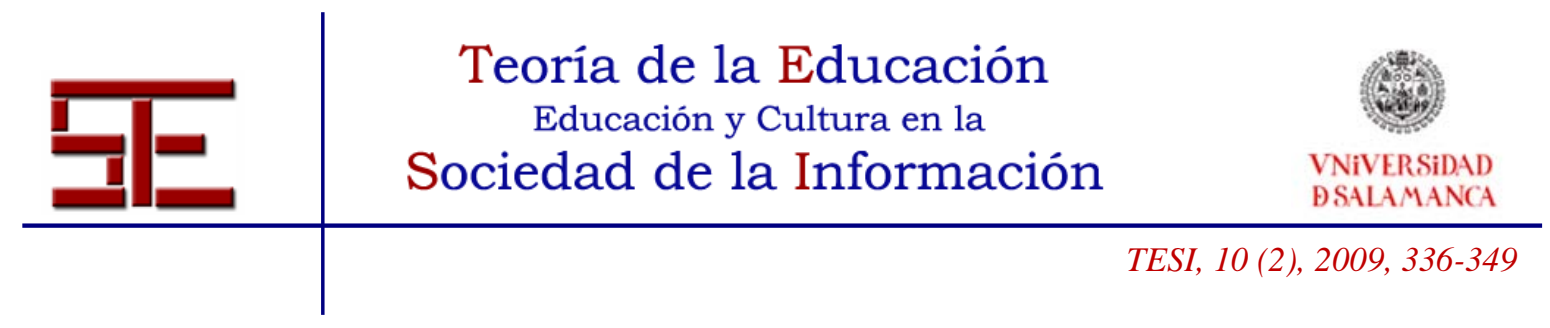

\title{
YOUNG COMMUNICATION: CONCERNING THE FASCINATION WITH AND THE EDUCATIONAL OFFERINGS OF THE NEW MEDIA
}

\begin{abstract}
This article responds to the question: Why do youth enjoy so much the languages of multimedia? After defining the characteristics of these languages, the role that the new technologies play in the imagination of the youth is analyzed; specifically studied are those factors that can contribute to the improvement of their learning and, in general, their education. Finally this article alludes to the cognitive processes that underlie the computer activities that youth undertake as well as to the forms of thought and communication that advance these new technologically based media.
\end{abstract}

Keywords: Communication, youth, multimedia languages, learning, multiliteracy, hypertext

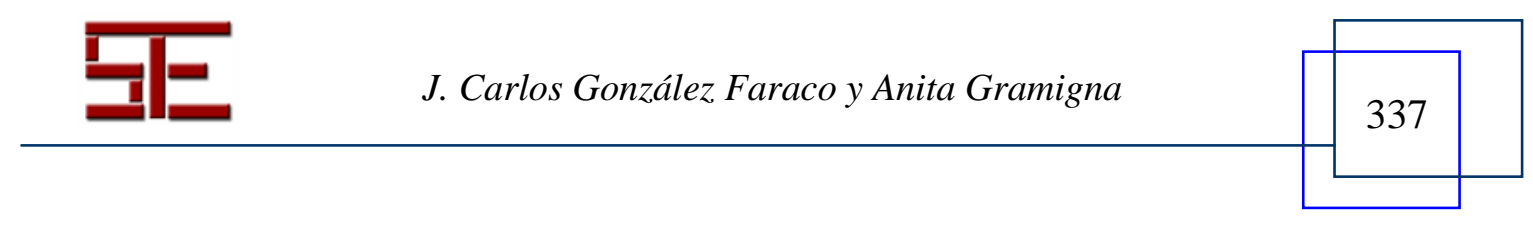




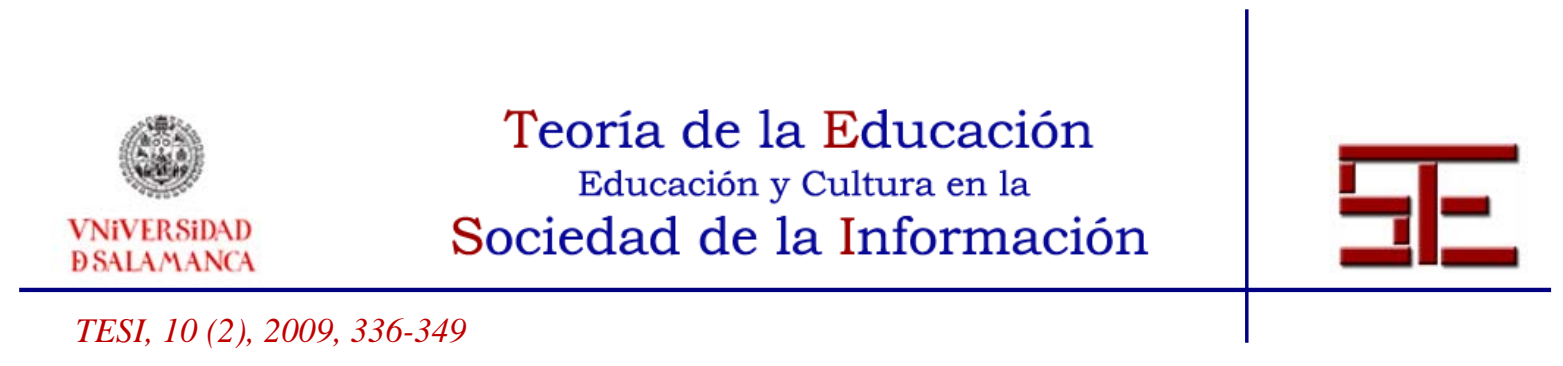

\title{
COMUNICACIÓN JOVEN: A PROPÓSITO DE LA FASCINACIÓN Y LA PRESTACIÓN EDUCATIVA DE LOS NUEVOS MEDIOS
}

\author{
J. Carlos González Faraco \\ faraco@uhu.es \\ Universidad de Huelva \\ Anita Gramigna \\ grt@unife.it \\ Universidad de Ferrara, Italia.
}

\section{1.- SEDUCIDOS POR LOS NUEVOS MEDIOS}

En nuestra cultura, la brecha entre los saberes de la generación joven y la adulta se ha ido haciendo paulatinamente más ancha y profunda, con evidentes problemas de comunicación y soledad para ambas. En este trabajo trataremos de afrontar la crucial cuestión de la valencia cognitiva de los lenguajes multimediales y de las transformaciones que, en sentido educativo, van apuntando las nuevas demandas culturales y profesionales.

Ante esta problemática, parece necesario, en primer lugar, preguntarse por qué los nuevos medios ejercen tan extraordinaria fascinación en los jóvenes. Al mismo tiempo resultaría altamente instructivo detectar aquellos factores que podrían ser valiosos para mejorar su motivación para el aprendizaje. No cabe duda de la importancia y el provecho que puede reportarnos ahondar en los procesos cognitivos que subyacen a las habilidades, las socializaciones e itinerarios formativos que los jóvenes experimentan con el ordenador y, no menos, en las diversas formas de pensamiento que pueden propiciar los nuevos lenguajes. Pero empecemos por la primera cuestión: ¿por qué estos lenguajes gustan tanto a los jóvenes?

En un principio, podemos hablar de al menos dos grandes razones que justificarían la poderosa atracción que los nuevos medios ejercen sobre los jóvenes. De un lado, la enorme familiaridad que han alcanzado $\mathrm{y}$, de otro, la potente dimensión lúdicocomunicativa que, con frecuencia, desarrollan. Las nuevas tecnologías, quién puede dudarlo, tienen un papel relevante en el imaginario de los adolescentes y enfatizan su protagonismo en los procesos de construcción del conocimiento, lo que puede favorecer de manera sustantiva su motivación para el aprendizaje.

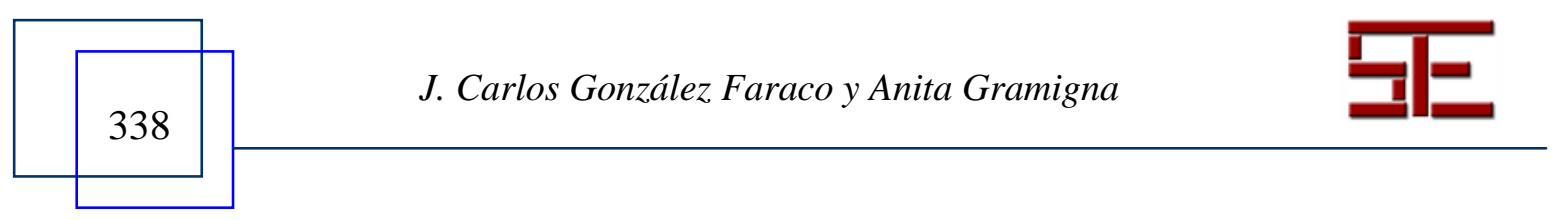




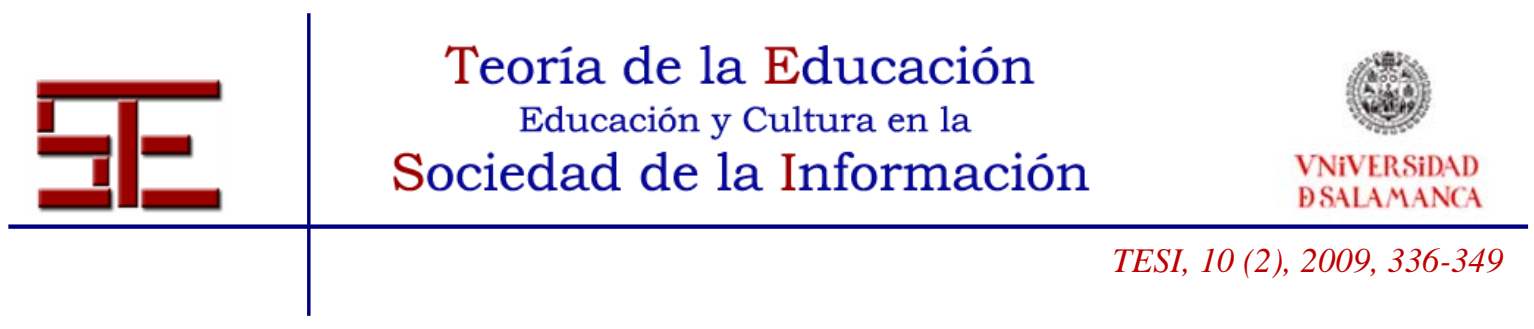

El componente lúdico del conocimiento, su profunda imbricación en las estructuras del imaginario, la dimensión evocativa, el sentido, en fin, de la aventura y del descubrimiento, son algunos de los factores que justifican el interés que el uso del ordenador despierta en los jóvenes. El aprendizaje -y más en general el proceso del conocimientono puede prescindir de la posibilidad de evocar y enriquecer los iconos de un imaginario que se ha ido sedimentando con las vivencias de cada sujeto.

Nos movemos dentro de una simbolización de la realidad con elevada carga de connaturalidad o verosimilitud, tal como se observa, sobre todo, en los videos didácticos, que utilizan imágenes, sonidos, colores y movimientos, en el marco de un esquema interactivo de aprendizaje. Caeríamos en un error si aceptáramos la ilusión de que el conocimiento se agota, por ejemplo, en la mera habilidad de reconocer el icono preciso sobre el que hay que clicar, o en la capacidad de recordar los sucesivos movimientos que hay que realizar, prescindiendo de la teorización, es decir, de su necesaria inserción en una dimensión metacognitiva. Si, en cambio, optamos por hacer el esfuerzo de comprender las gramáticas implícitas en estos movimientos, estrategias y simbolizaciones, nos resultará más fácil calibrar por qué todo ello puede aportar interesantes repercusiones a la reflexión sobre la idea de saber que hemos madurado. Pensamos que ésta debería ser una de las finalidades de la alfabetización informática, tan presente ya en muchas escuelas.

La adopción de esta perspectiva, además, podría producir un efecto muy positivo en la innovación didáctica (Bolter, 2002). Cualquier aprendizaje está, en efecto, estrechamente conectado, en una relación dialéctica, con nuestra personal epistemología del conocimiento. La adquisición de los saberes puede verse beneficiada u obstaculizada por la capacidad de reconocer o no como significativos, cognitivamente hablando, procesos e informaciones. Esta capacidad, educativamente orientada, puede además ayudar al adolescente a elaborar nuevos mapas cognitivos y, como consecuencia, a multiplicar sus estrategias y sus oportunidades de resolver problemas.

Para ello, resulta primordial, de un lado, considerar los factores de innovación educativa que pueden brindar las nuevas tecnologías, bien sea por ese clima de conexión e inmersión al que nos referíamos antes, bien por esa interactividad que subraya el protagonismo del niño en los procesos de exploración y construcción de los conocimientos. Se trata de factores que, unidos a otros, están en la base de la motivación para el aprendizaje y condicionan conjuntamente el clima escolar, es decir, contribuyen a crear el marco de bienestar o de malestar que la escuela ofrece a sus jóvenes usuarios.

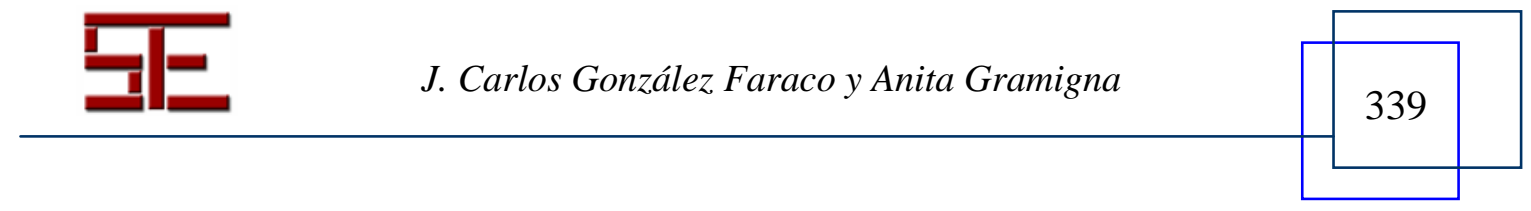




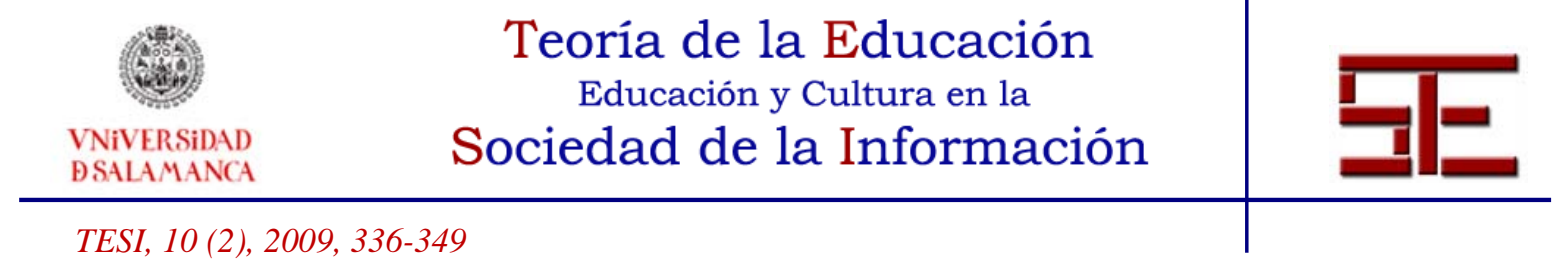

De hecho, las estrategias de pensamiento y de construcción del saber que se desarrollan con los nuevos lenguajes pueden ayudar a acortar la distancia entre las vivencias del adolescente - comprendidas las que tiene fuera de la escuela en su tiempo libre- y los saberes disciplinarios, y así poner de manifiesto su participación en la construcciónexploración del conocimiento. Todo lo cual, insistimos, puede redundar satisfactoriamente en el aprendizaje y en el bienestar escolar.

Pero no todo es oro lo que reluce. También el nuevo mundo de la informática esconde zonas en sombra que despiertan dudas y críticas diversas. Es un hecho que los jóvenes están cada día más ligados a estas máquinas fantásticas, con las que se relacionan mediante unos pocos gestos óculo-viso-manuales, postergando quizás otras actividades lúdico-motoras. Pero éste es un problema que trasciende la utilización de los nuevos medios en la escuela y concierne a un discurso mucho más general sobre estilos de vida, relaciones sociales y ambientes culturales. En cualquier caso, lo que importa es comprender los símbolos que construyen las estrategias de pensamiento, los modelos de socialización y los procesos de adquisición del conocimiento. Y saberlos manejar con sentido formativo. De ahí el relevante papel de la pedagogía y de la escuela en el juego de recíproco intercambio entre teoría-praxis-teoría, con objeto de hacer posible una mayor y mejor comunicación.

Los nuevos medios son, en suma, instrumentos de conocimiento y comunicación muy cercanos a la experiencia de los jóvenes, a sus vivencias cotidianas y, por ende, son para ellos reconocibles y familiares. Sin embargo, la pantalla del ordenador es tan sólo un modo, entre otros tantos, de vivir el conocimiento. Se suele comentar que hoy el pensamiento está siendo sustituido por la mirada, pero lo que quizás ocurre es que se está pensando de una manera diferente, pues son diferentes los lenguajes en acción (Galimberti, 1999). En la raíz de esta atracción que anima tanto a los jóvenes a pasar horas y horas delante del ordenador, puede que esté el deseo de conseguir una inmersión una participación y una inclusión que la virtualidad de los nuevos medios favorece, al menos en parte, gracias a la peculiaridad de sus lenguajes.

En efecto, la virtualización que deriva del código alfabético a través del libro, por poner como ejemplo el instrumento más tradicional y consolidado del saber occidental, es extremadamente abstracta. Es decir, se sirve de una organización de signos y códigos que está muy alejada de la realidad que pretende representar. En la pantalla del ordenador, en cambio, aparecen imágenes que, ensambladas con sonidos y movimientos, presentan una fuerte con naturalidad con el objeto o la situación que intentan evocar. Este hecho, al menos en un primer nivel de lectura, vuelve el

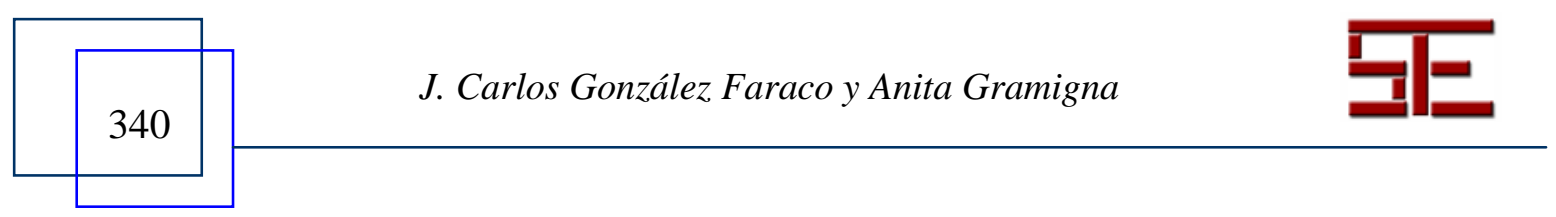




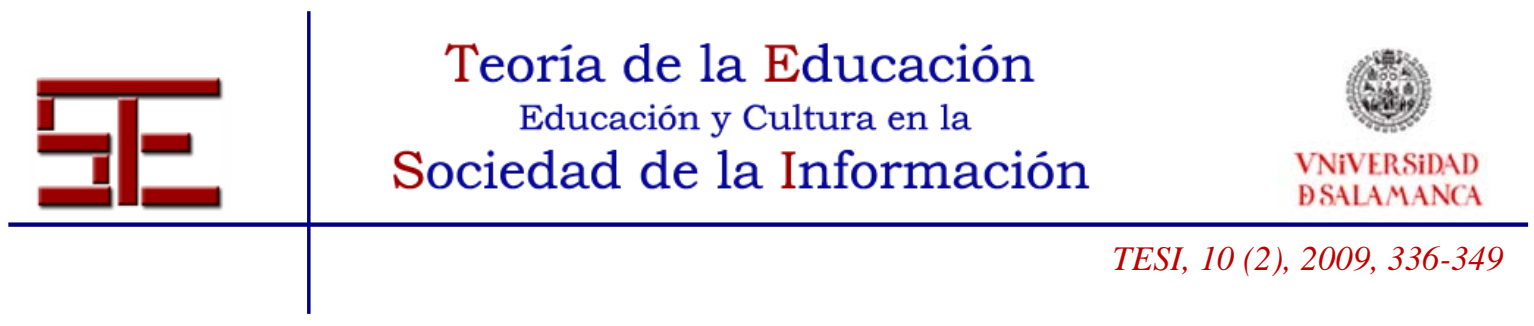

instrumento-ordenador más cercano que el libro a la experiencia del adolescente (Roversi, 2004).

Las gramáticas que se desarrollan en la pantalla, su virtualidad paradójicamente menos "virtual" que la de los libros y la escuela, responden a la necesidad de reconocer en el instrumento un valor de nexo con la persona misma (Paccagnella, 2000). Esta conexión sujeto-máquina hace posible su ingreso e inclusión en el mundo que aparece mágicamente en la pantalla, abriéndole la puerta de la fantasía, del juego, de la acción y de una cierta forma de pensamiento. Esta inmersión reduce aún más el grado de abstracción que la experiencia con el ordenador le propone, pues el adolescente se ve proyectado dentro de un mecanismo y un proceso de exploración del saber, de narración de su propia vivencia y de construcción del sentido del propio universo simbólico.

Ahora bien, si el ordenador representa una especie de prolongación del sí-mismo y, a la par, de ambiente líquido en el que habitar, el sujeto se convierte a su vez en parte de ese ambiente, percibiéndose a sí mismo como parte integrante de él y además, gracias a sus relaciones con el instrumento, como parte de la misma máquina, es decir, como parte de esos vínculos que la máquina le permite y le solicita. Como escribe García Carrasco (2006), "los imaginados lugares del ciberespacio ofrecen mundos paralelos de sí mismo, territorios fantásticos o en la fantasía, cuya frecuencia de habitación termina por formar parte de la vida real de los actores. No se trata solamente de una injerencia lúdica del imaginario en la vida real, ni una mera huida de la vida real para ensimismarse en el imaginario, sino que se trata propiamente de una interferencia en el significado habitual de lo que entendíamos por dominios de la identidad y de la autenticidad, interferencia que puede terminar modificando, tanto la identidad como la autenticidad. En todo caso, estamos ante nuevos dominios de prácticas culturales”.

La constatación de todo ello pone necesariamente en tela de juicio las más establecidas y acendradas ideas de cultura, conocimiento y educación. Ya no estamos meramente ante un sujeto que enseña o que, en el mejor de los casos, acompaña al aprendiz por los caminos más o menos disciplinarios de la enseñanza. Dentro de la lógica "mass-medial" y "multimedial", que ya irrumpe con fuerza en el horizonte inmediato, lo principal es que el sujeto se experimenta a sí mismo a través de la utilización “íntima” del instrumento. Y la llamamos “íntima” porque el instrumento puede ser vivido como continuación y refuerzo de las propias capacidades, porque hace viable el deseo de conexión e inmersión, y porque, gracias a todo ello, el adolescente participa finalmente en los procesos de construcción y definición de sí-mismo.

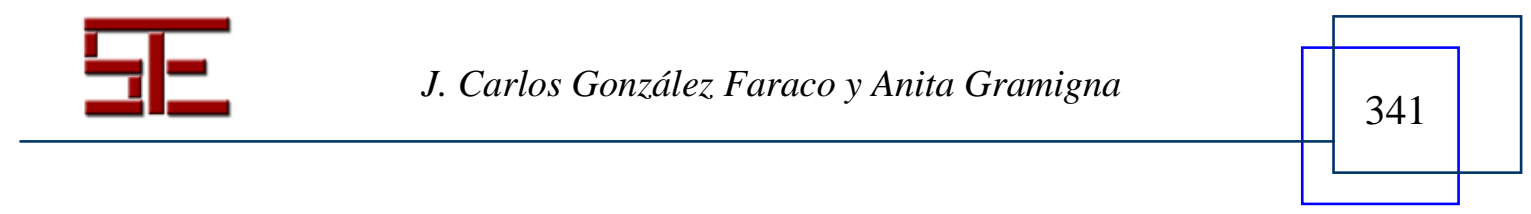




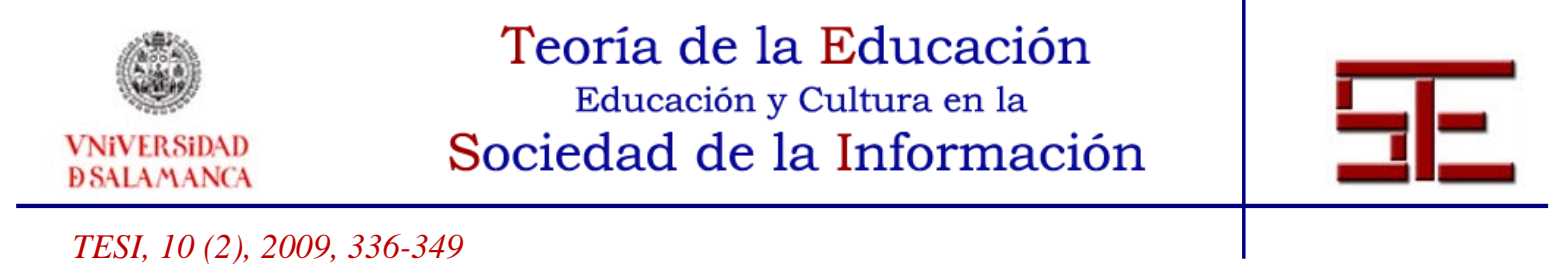

El ordenador "funciona" porque pone en juego su potencial en las interacciones, presenta "textos" abiertos y reenvía al usuario hacia múltiples relaciones e infinitos enlaces. De este modo, éste toma parte activa en la exploración, adquisición y construcción del conocimiento, mientras trabaja en favor de su autodeterminación mediante un atrezzo que, aunque se refiera a mecanismos de simbolización de lo real, es vivido como menos abstracto que las viejas tecnologías de la cultura. Así, persona, tecnología, lenguaje y conocimiento terminan por ser categorías más fluidas que antaño, pues una es prolongación de la otra, y ésta confunde su identidad con la de aquélla, en una intercomunicación y en una fusión, inacabables.

Pero para ilustrar mejor nuestro argumento, detengámonos por un momento en un ejemplo paradigmático, el de los videojuegos, verdadero crisol de los lenguajes multimedia, objeto de irresistible atracción para los jóvenes y, como no podía de ser otro modo, un fenómeno con sus luces y con sus sombras (Sánchez i Peris, 2008; Etxebarría, 2006).

\section{2.- LOS VIDEOJUEGOS Y LA BRECHA INTERGENERACIONAL}

Cuando "videojuega", el adolescente se vale de diversos tipos de inteligencia, contrariamente a lo que sucedía, y en buena medida sigue sucediendo, en un medio escolar de tipo tradicional, en el que los procesos de enseñanza-aprendizaje propician un acercamiento al saber de tipo abstracto, secuencial y escrito, mediante el uso exclusivo de un código alfabético. El pensamiento que vuela con las aventuras de los juegos de ordenador es, en cambio, de tipo conectivo, pues combina y entrelaza diversos códigos lingüísticos (Sánchez y Alfageme, 2002; Gee, 2004). Esto lo empuja, inevitablemente, a recodificar sus gramáticas y a modificar sus estrategias y modelos, en una concertación recíproca constante. Y lo puede orientar, finalmente, hacia un pensamiento de tipo creativo, mucho más eficaz en la formulación de hipótesis y en el hallazgo de soluciones a los problemas.

En la pantalla del ordenador, además de conductas de tipo secuencial, reflexivo e intelectual, actúan los impulsos, la subjetividad y las emociones (González y Blanco, 2008), habilidades y competencias que, a un nivel elevado, caracterizan a un sujeto, es decir, a alguien que elabora mapas mentales y reorganiza sus modelos cognitivos en función de los contextos. O sea, alguien que inventa, en el sentido de que desarrolla eficientemente conexiones instantáneas a más niveles de significado. El tipo de pensamiento que se activa de este modo vuelve funcional la comunicación entre

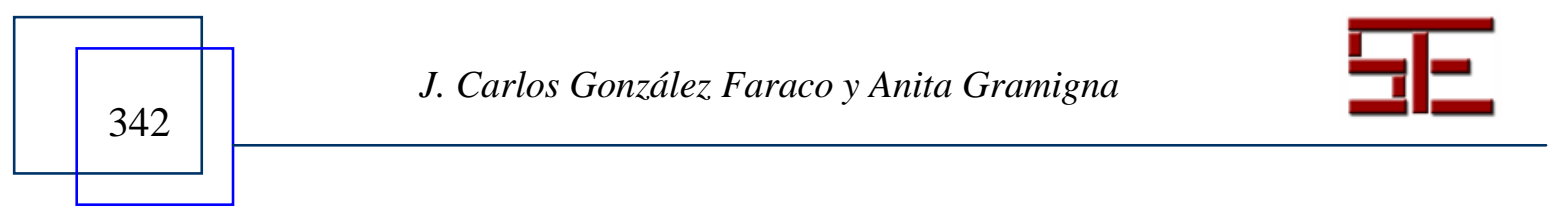




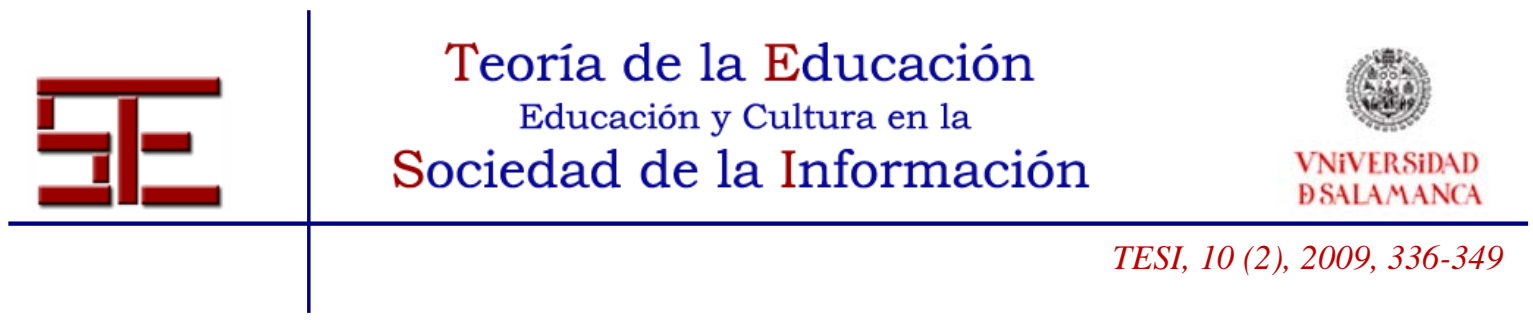

lenguajes diferentes, y entre éstos y el medio, según una estructura y unos itinerarios que nos recuerdan el modelo interconectivo de la red. No es de extrañar que para una perspectiva epistemológica tradicional, vertical, aristotélica y jerárquica, resulte tan difícil la lectura de los procesos de aprendizaje que los videojuegos, y en general las nuevas tecnologías, promueven.

Es cierto que la naturaleza de los mecanismos de construcción del conocimiento no es la misma que la de los procesos de su puesta en práctica, pero no es menos cierto que su interrelación los condiciona recíprocamente. La activación y la adquisición de un aprendizaje son fenómenos radicalmente distintos, pero la idea que tengamos de la naturaleza de esa adquisición puede influir en el reconocimiento o, mejor aún, en la interpretación del aprendizaje mismo y de su utilización. De hecho, nuestras más consolidadas tradiciones académicas y culturales desde Platón, han infravalorado durante mucho tiempo el valor formativo de la emoción, de lo irracional, de lo subjetivo, en una palabra, del pathos, otorgándole solamente plena dignidad gnoseológica al logos (Mélich, 2006).

El mundo, el individuo y el conocimiento han sido interpretados $\mathrm{y}$ definidos principalmente mediante esta categoría, que ha quedado así autolegitimada. Puede que estemos coartados, más de lo que suponemos, por los posos de esta antigua tradición gnoseológica que está en el origen del pensamiento filosófico occidental y del lenguaje alfabético que hizo posible su nacimiento. Puede que de ello provenga la desconfianza y el temor que muestran quienes se acercan a las nuevas tecnologías con una actitud que oscila entre el pesimismo cósmico y la nostalgia de un pasado áureo. Y puede que en todo ello encontremos la razón de nuestra incompetencia adulta en los juegos de ordenador.

En la pantalla entramos en desigual batalla con chicos jóvenes que se mueven libremente en una red de elementos interconectados, cuya coherencia responde a la lógica del juego o a la de los procedimientos cognitivos del adolescente. Cualquier acontecimiento es importante, pero sólo es plenamente comprensible cuando se lo observa en relación con otros. Ninguno es, en realidad, verdaderamente imprescindible o fundamental. Sin embargo, nosotros, los adultos, siempre esperamos que a una jerarquía de acciones correctamente ordenadas le corresponda un solo fin o al menos que siga una dirección inevitable, la más justa. Nuestra ideología estratégica es, como ya hemos dicho, vertical, abstracta, lineal, secuencial, y no admite encrucijadas, ni

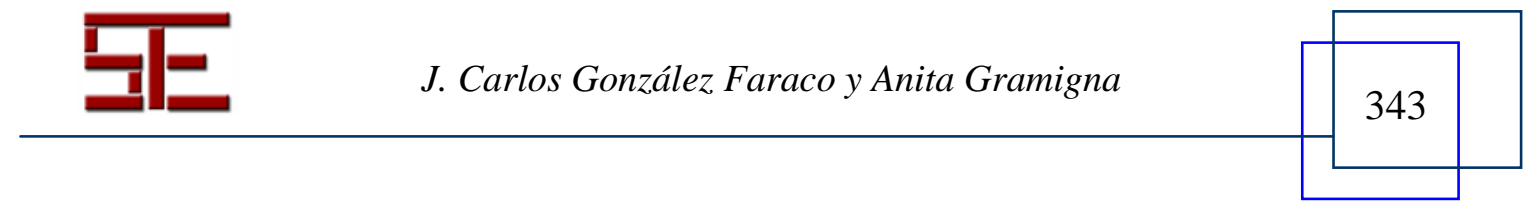




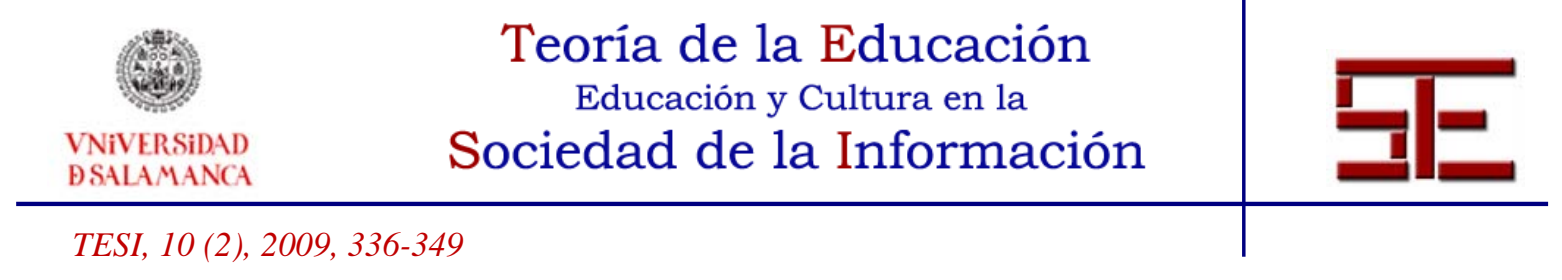

laberintos, pues es unidireccional. Lo reticular nos resulta extremadamente extraño e incluso inquietante.

\section{3.- POLÍGLOTAS INFORMÁTICOS}

"La red -escribe U. Margiotta (1997, 17)- habla muchos alfabetos. Lo que exige el compartir por entero procedimientos, estrategias, también ambientes formativos, pero sobre todo estilos, conductas y actitudes que aseguren que los hablantes sean y se reconozcan recíprocamente como autores multialfabetizados (...). El multialfabeto es un mapping processor, un constructor de mapas mentales. Políglota es quien usa muchas lenguas. Usar lenguajes diversos significa crear continuamente mapas mentales, nuevos mapas cognitivos, en función de los contextos de uso de referencia de los procedimientos cognoscitivos o de acción en los que se está involucrado. Significa producir estrategias adecuadas para la resolución de los problemas y consecuentemente métodos y perspectivas competentes para la exploración y el diálogo. Dicho más claramente, el multialfabeto es quien crea escenarios expertos de interacción, conocimiento y relación”. Efectivamente, la combinación de códigos presupone, de un lado, unidades lingüísticas fuertemente connaturales (como, por ejemplo, la imagen unida al sonido y al movimiento típica del lenguaje televisivo); de otro, conduce a nuevas convenciones en la utilización del alfabeto.

Este último proceso implica la formalización de una técnica -es decir, un alfabeto- ya de por sí intensamente formalizada, con alta densidad simbólica $\mathrm{y}$, por tanto, potentemente abstracta (Bruner, 1997). Se trata de una curiosa combinación que anuda los opuestos (o que, al menos, a primera vista nos lo parecen): la figuración realista y la abstracción, la oralidad y la escritura. La fusión “imagen/sonido/movimiento", el mismo alfabeto enriquecido por elementos paralingüísticos e ideográficos (los smileys, por ejemplo) u onomatopéyicos, que tan ajenos le eran tradicionalmente, han hecho posible la emergencia de un nuevo lenguaje y, con él, insólitas metáforas del saber y diferentes orientaciones gnoseológicas. En este nuevo lenguaje, no sólo la abstracción convive holgadamente con la figuración realista, también la oralidad se insinúa en el pensamiento alfabético: síntesis en el análisis.

En red nuevos esquemas mentales se abren paso y toman forma, pero obviamente alcanzan también los entresijos de la vida cotidiana, que se enriquece -o se empobrece, según se mire- con raros elementos paralingüísticos. Se atisba una nueva ecología de signos, mientras el mundo on line permea el mundo off line en un inagotable juego de mutuo condicionamiento. De este modo, el sujeto participa activamente en los procesos

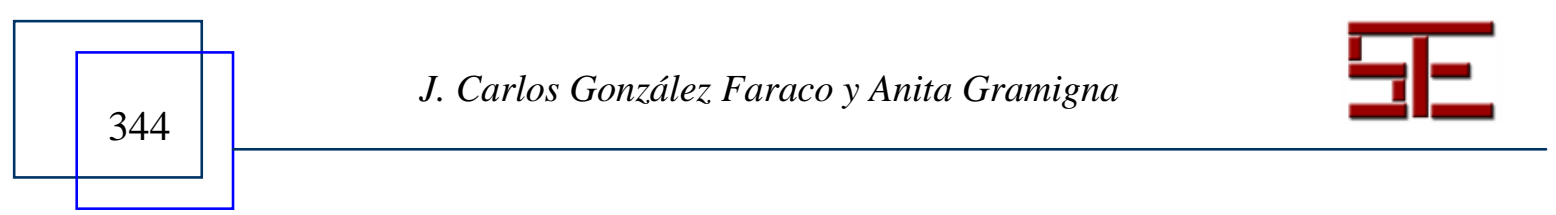




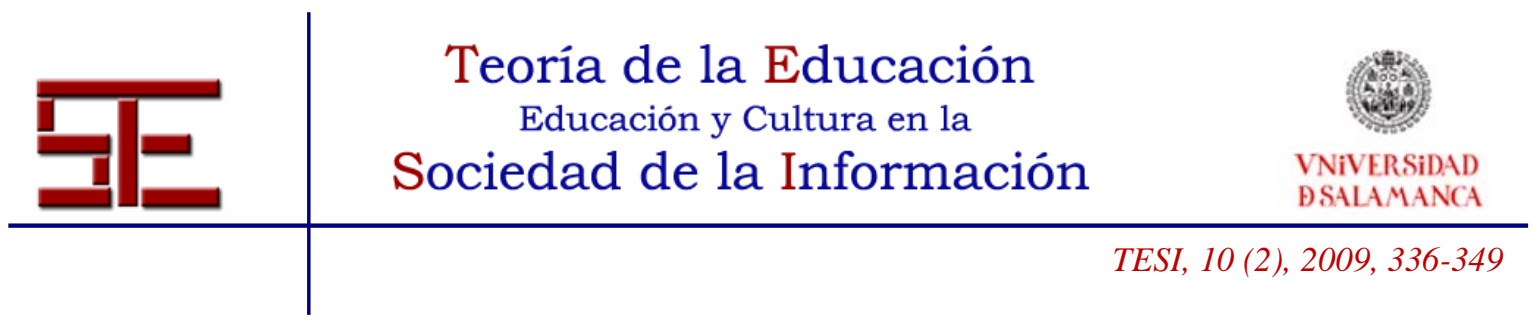

de invención cuando opera con sus múltiples códigos de transcripción. Aún más, la invención individual se vincula a la colectiva con sentido conectivo produciendo vías inéditas de socialización. Los impactos educativos de este fenómeno tan complejo como cambiante constituyen el gran nodo pedagógico de nuestra frenética y agitada época.

El encuentro de códigos que facilita el uso del ordenador responde a la naturaleza y a la complejidad de esos nexos, que son siempre socio-antropológicos, por tanto lingüísticos, y que se cruzan en planos diferentes, produciendo una estructura que difiere nítidamente de las tradicionales categorías de lectura. Lo que explica las críticas al alejamiento, más o menos cierto, de la escuela del mundo contemporáneo y que, traducido al lenguaje del sentido común, induce a afirmaciones como que la escuela no sigue el ritmo de los tiempos, que no está en sintonía con el mundo del trabajo, con las exigencias del mercado, con Europa, etc.

Es innegable que las nuevas gramáticas del saber están más próximas a los estilos cognitivos de los jóvenes. Éstos ponen de manifiesto, más o menos abiertamente, esta proximidad simbólica entre las múltiples conexiones del lenguaje en red y el sistema social en el que viven. Ponen en marcha nuevas simbolizaciones de sus experiencias vitales, crean microcomunidades on line, fabrican convenciones normativas, experimentan formas de relación, elaboran diversas prácticas de autorrepresentación y autodeterminación: se sumergen en una nueva gramática del conocimiento.

El sistema simbólico que sirve de referencia a los jóvenes se organiza también, aunque no sólo, en un estructura reticular que, por una parte, responde a una organización diferente del conocimiento y sus códigos de acceso; por otra, formaliza, inexcusablemente, una sistematización lingüística que se salta los pasajes fundamentales de la gramática tradicional, volviéndolos implícitos o sustituyéndolos con elementos y relaciones nuevos.

"La radical transformación de lo moderno en postmoderno -escriben Alimenti y Margiotta (1997, 56)- acaso radica en que el hombre contemporáneo ya no está dispuesto a adherirse a un proyecto de civilización en términos de ascesis colectiva (en cuanto secularizada o invertida en sus términos), sino más bien en términos de creatividad explícita y de autogestión de la propia especificidad. Acepta la ruptura de la tradición, los compromisos entre objetivos sociales y potenciación de los medios de producción, pero para explorar hasta el fondo la dialéctica entre medios y fines”.

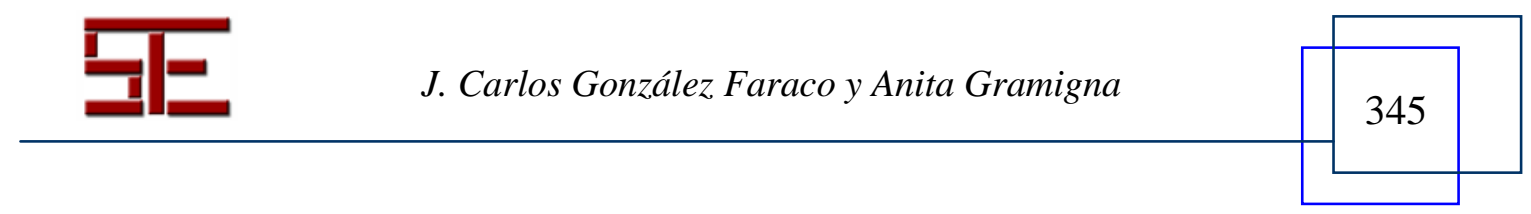




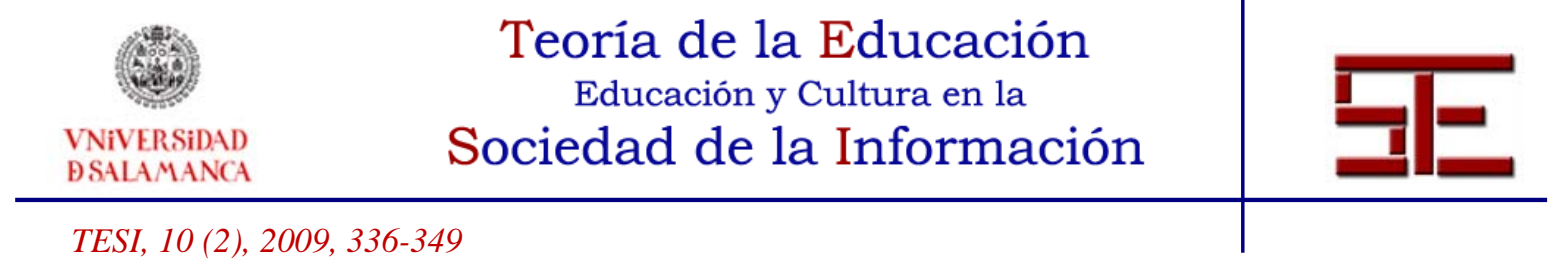

Desde el punto de vista cognitivo, el lenguaje en red constituye un estímulo extraordinariamente sugestivo para el pensamiento productivo, ese pensamiento que es capaz de convertir en estrategia de investigación los factores problemáticos de cualquier situación. Lo que obviamente no significa que, antes de que proliferaran las nuevas tecnologías, no hubiera ámbitos tecnológicos y formas del lenguaje que favorecieran esta dimensión del pensamiento. Lo que se quiere subrayar es que hoy en día los nuevos medios pueden ser empleados como ambientes formativos válidos también desde este punto de vista, sobre todo si en las instituciones escolares se conocen sus gramáticas y se experimentan las nuevas formalizaciones de manera intencional. De hecho, dentro de este nuevo contexto formativo, las estrategias de pensamiento siguen caminos en parte originales y llegan a conclusiones soslayando etapas que antes eran ineludibles, o estableciendo conexiones con una lógica renovada. Ni mejor ni peor, diferente y, por ello, sugestiva, pues brinda nuevas herramientas que, yuxtapuestas a las que tenemos por tradicionales, amplifican en contenidos e instrumental los horizontes de nuestra inteligencia.

\section{4.- HIPERTEXTOS E HIPERCOMUNICACIÓN}

La interacción en red conlleva una inmersión lógica, emocional, sensorial y sensomotora del sujeto que aprende y hace al mismo tiempo y que, también al mismo tiempo, conecta significados de un código a otro, siguiendo mapas conceptuales, estrategias intelectuales, vivencias emocionales, disposiciones estéticas y opciones axiológicas. La experiencia humana se presta a una lectura menos univoca de la que sugiere el libro, una lectura reticular que recupere la ritualidad oral e impulse a la par la sugestión, la emocionalidad y la racionalidad.

En ello, es decir, en su compleja metacognitividad, radica el extraordinario valor educativo de los lenguajes multimedia. El sujeto que se mueve de manera experta en el mundo informático, por ejemplo en el hipertexto, construye el conocimiento mediante la elaboración de tramas relacionales que se desarrollan entre lenguajes diversos y que, por tanto, se sirven simultáneamente de diversas formas de inteligencia. Se abre a varias perspectivas cognitivas, recoge información siguiendo un procedimiento lógico, afectivo, estético y sensorio-motor. No sólo se atiene a un pensamiento abstracto, sino que se vale de las distintas estrategias intelectivas que están en la base de las distintas formas lingüísticas. Utiliza con sentido creativo un pensamiento conectivo y está dispuesto a reconfigurar su propia teoría del conocimiento ante nuevas experiencias cognitivas. Pero, naturalmente, hablamos sólo del navegante experto, no del chico que

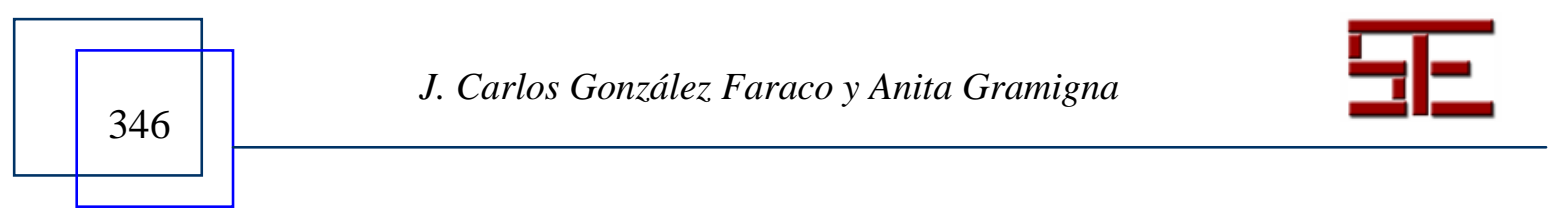




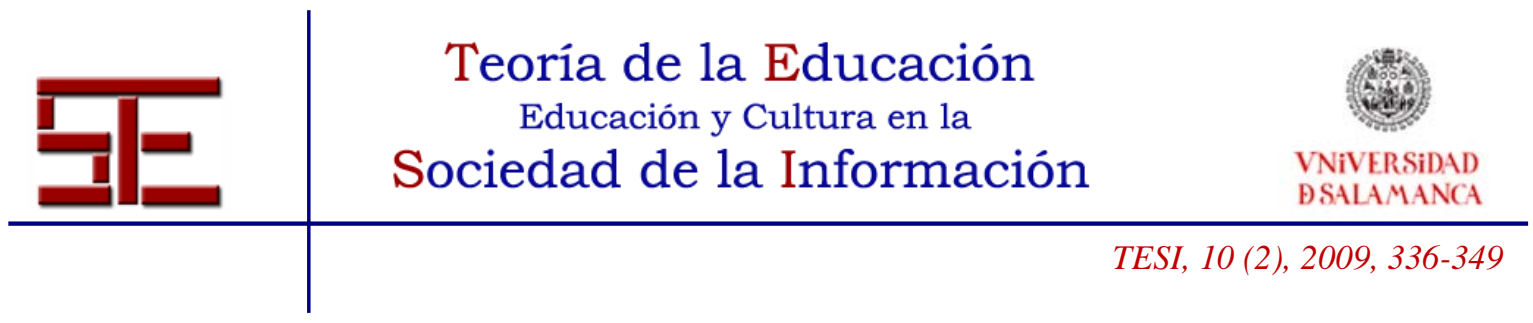

se ve literalmente atrapado por el juego trivial y estereotipado de un videojuego banal (Bonaiuto, 2002).

Se puede consultar el hipertexto desde puntos de partida diversos, autónomos e independientes, porque el hipertexto se libra de la sucesión lineal de los capítulos y de los párrafos del libro, donde esta cualidad sólo es concebible desde un punto de vista conceptual. El hipertexto dialoga a través de una interfaz gráfica, cuyas informaciones están organizadas de modo que el usuario puede elegir sus propios itinerarios de lectura, recurriendo a enlaces o materiales. Estas características, que hemos señalado, son las mismas que las del soporte papel y las del código alfabético, sólo que multiplicadas por mil gracias a la enorme potencialidad tecnológica de la interfaz, con sus funciones de cortar y pegar, buscar y reemplazar, visualizar con zoom y realizar cambios muy rápidos.

La hipertextualidad transforma el libro en texto electrónico, en byte, lo priva de la sólida y pesada dimensión que le da el papel y que sólo puede ser recuperada imprimiendo o, mejor aún, descargando el documento de la memoria del ordenador. Pero, a la vez, lo asocia a otros códigos con los cuales teje una interrelación sistémica, es decir, una especie de formalización de la formalización. Por otra parte, el hipertexto permite al lector intervenir dentro del propio sistema convirtiéndolo en una suerte de coautor, pues el espacio de la informática sobrepasa los límites de la materialidad del papel y la hoja, haciendo posible que cada uno aporte alternativas significativas para la construcción de vías propias de conocimiento.

A nuestro juicio la teoría de la educación y, más específicamente, la didáctica tienen como objetivo prioritario transformar los saberes para optimizar el aprendizaje y, en consecuencia, potenciar la intervención educativa. Es evidente que la estructura hipertextual comporta, por su propia naturaleza, la transformación, recodificación y formalización de los conocimientos en mapas conceptuales que conciernen a una pluralidad multiforme de lenguajes, de medios, en suma.

Tenemos por delante todo un mundo de nuevas oportunidades formativas a explorar para utilizar de manera consecuente la tecnología multimedia, pero también para contemplar desde una óptica distinta toda la tecnología del conocimiento -desde la oral a la escrita, y desde ésta a la informática- y su relación esencial con el contexto social. En esta época fragmentada, desorientada e incierta, es un eje pedagógico clave la tarea de ayudar a los jóvenes navegantes a construir instrumentos críticos para la exploración

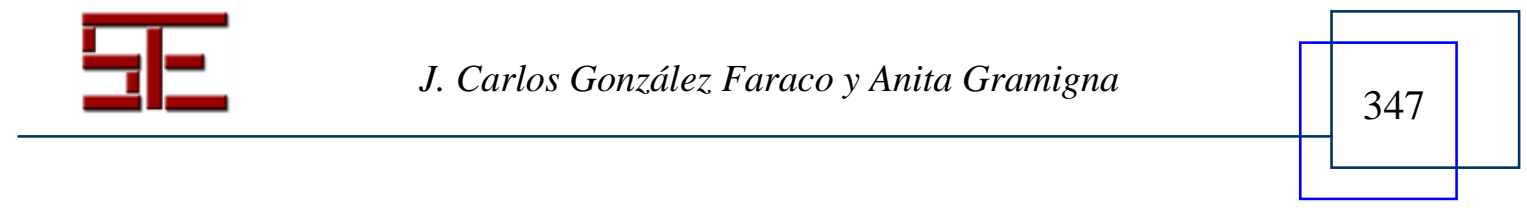




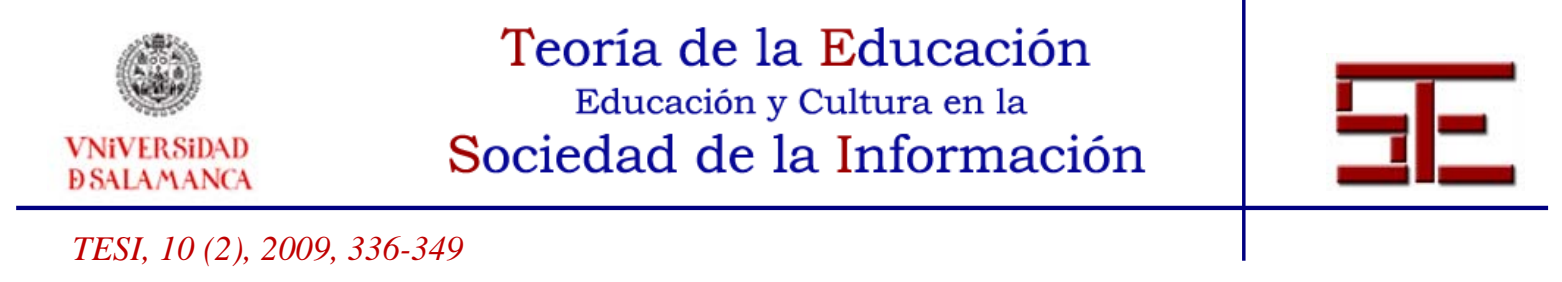

y creación del conocimiento, a partir de las emergencias educativas que nuestro mundo nos impone y de los caminos existenciales que caracterizan la vida de cada persona (Boni, 2006). En este sentido, es primordial estudiar las gramáticas de los lenguajes multimedia y las formas de pensamiento que activan para comprender sus estructuras, inteligencias y seducciones más o menos ocultas.

\section{5.- REFERENCIAS}

ALIMENTI, A. y MARGIOTTA, U. (1997): Perzecione tecnologica e mutazione antropológica, en MARGIOTTA, U. (ed.) Pensare in rete. La formazione del multialfabeta. Bolonia, Clueb.

BOLTER, J. D. y GRUSIN, R. (2000): Remediation. Understanding New Media. Cambridge, Massachusetts, The MIT Press.

BONAIUTO, M. (ed.) (2002): Conversazioni virtuali. Come le nuove tecnologie cambiano il nostro modo di comunicare con gli altri. Milán, Guerini e Associati.

BONI, F. (2006): Teorie dei media. Bolonia, Il Mulino.

BRUNER, J. (1997): La educación puerta de la cultura. Madrid, Visor.

ETXEBARRÍA, F. (coord.) (2006): Utilización didáctica de los videojuegos, Comunicación y Pedagogía, 216 (monográfico). Disponible en: http://www.comunicacionypedagogia.com/publi/infcyp/indice/216.htm [consulta 2008, 10 de diciembre]

GALIMBERTI, U. (1999): Psiche e techne. L'uomo nell'età della tecnica. Milán, Feltrinelli.

GARCÍA CARRASCO, J. (2006): Las emociones en el “territorio” on-line, Teoría de la Educación: Educación y Cultura en la sociedad de la información, 7 (2). Disponible en: http://www.usal.es/ teoriaeducacion/rev_numero_07_02/n7_02_joaquin_garcia.pdf [consulta 2008, 18 de Diciembre]

GEE, J. P. (2004): Lo que nos enseñan los videojuegos sobre el aprendizaje y el alfabetismo. Archidona. Aljibe.

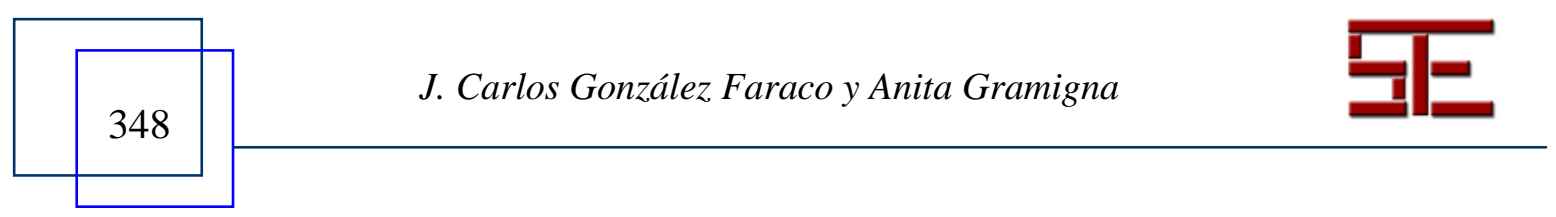




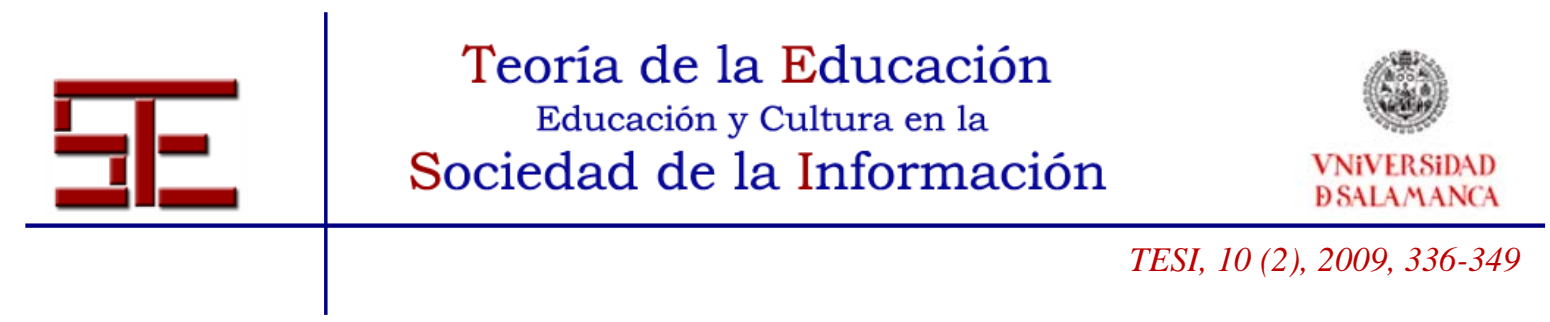

GONZÁLEZ, C. S. y BLANCO, F. (2008): Emociones con videojuegos: incrementando la motivación para el aprendizaje, Teoría de la Educación: Educación y Cultura en la Sociedad de la Información. 9 (3). Disponible en: http://www.usal.es/ teoriaeducacion/rev_numero_09_03/n9_03_gonzalez_blanco.pdf [consulta 2008, 21 de Diciembre]

MARGIOTTA, U. (ed.) (1997): Pensare in rete. La formazione del multialfabeta. Bolonia, Clueb.

MÈLICH, J. C. (2006): Transformaciones. Tres ensayos de filosofía de la educación. Buenos Aires, Miño y Dávila.

PACCAGNELLA, L. (2000): La comunicazione al computer. Bolonia, Il Mulino.

ROVERSI, A. (2004): Introduzione alla comunicazione mediata dal computer. Bolonia, Il Mulino.

SÁNCHEZ, P. y ALFAGEME, B. (2002): Aprendiendo habilidades con videojuegos, Comunicar, 19, 114-119.

SÁNCHEZ I PERIS, F. J. (coord.): Videojuegos: una herramienta educativa del "homo digitalis”, Teoría de la Educación: Educación y Cultura en la Sociedad de la Información, 9 (3) [monográfico en línea]. Disponible en: (http://www.usal.es/ teoriaeducacion/rev_numero_09_03/) [consulta 2008, 27 de Noviembre]

Para citar la presente editorial puede utilizar la siguiente referencia:

González faraco, j. C. y Gramigna, A. (2009). Comunicación Joven: A propósito de la fascinación y la prestación educativa de los nuevos medios, en Ortega Sánchez, I. y Ferrás Sexto, C. (Coord.) Alfabetización Tecnológica y desarrollo regional. Revista Electrónica Teoría de la Educación: Educación y Cultura en la Sociedad de la Información. Vol. 10, n 2. Universidad de Salamanca, pp. 336-349 [Fecha de consulta: $\mathrm{dd} / \mathrm{mm} /$ aaaa $]$.

http://campus.usal.es/ revistas_trabajo/index.php/revistatesi/article/view/7520/7553

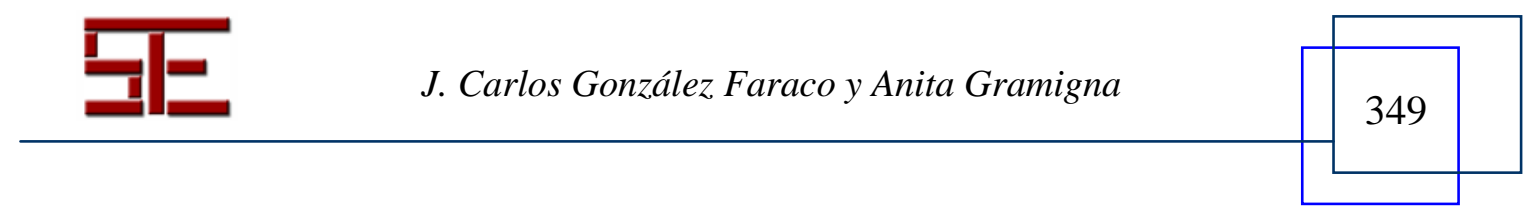

